\title{
Removal of cranial springs after spring-mediated cranioplasty
}

\author{
${ }^{*}$ Christopher L. Kalmar, MD, MBA,1 Jordan W. Swanson, MD,1 Sameer Shakir, MD,1 \\ Alexander M. Tucker, MD, ${ }^{2}$ Benjamin C. Kennedy, MD, ${ }^{2}$ Phillip B. Storm, MD, ${ }^{2}$ \\ Gregory G. Heuer, MD, PhD, ${ }^{2}$ Scott P. Bartlett, MD, ${ }^{1}$ Jesse A. Taylor, MD, ${ }^{1}$ and \\ Shih-Shan Lang, MD²
}

Divisions of ${ }^{1}$ Plastic and Reconstructive Surgery and ${ }^{2}$ Neurosurgery, Children's Hospital of Philadelphia, Pennsylvania

Cranial spring hardware is generally removed 3 months after placement for spring-mediated cranioplasty. Spring removal is performed as an outpatient procedure under general anesthesia in approximately 15 minutes through the incision locations of the index procedure. Herein, the authors provide a multimedia demonstration of cranial spring hardware removal after spring-mediated cranioplasty for sagittal craniosynostosis.

The video can be found here: https://vimeo.com/511179695

https://thejns.org/doi/abs/10.3171/2021.1.FOCVID20102

KEYWORDS sagittal; craniosynostosis; springs; removal; technique; video

\section{Transcript}

0:25 Timeline. Cranial springs are generally removed approximately 3 months after placement for sagittal craniosynostosis, which reflects several weeks of active expansion followed by about 2 months of consolidation. ${ }^{1-8}$

0:42 Local Anesthesia. After general endotracheal anesthesia is induced, local anesthesia containing epinephrine is infused in the patient's scalp incision. The patient is generally left in supine position.

0:52 Incision. After prep and drape, the previous scalp incisions are opened to the subgaleal plane, with care taken to protect the underlying cranial bone regenerate.

1:00 Subgaleal Undermining. Subgaleal undermining is performed over the midportion of the springs.

1:07 Dissection of Spring Arms. Dissection of each of the spring arms is performed to its footplate using tenotomy scissors and Obwegeser elevator.

1:13 Springs Elevated and Cut. Each spring is elevated off of the regenerate and then cut with heavy wire cutters in the midline.

1:19 Springs Removed. Each hemispring is carefully isolated from its surrounding soft tissue. Heavy needle driver is used to grasp each spring near its footplate; then the spring is axially rotated so that the footplate is retracted from its subcranial position and the hemispring is removed. Rarely, a Kerrison or narrow rongeur can be used to remove cranial bone immediately adjacent to the footplate if it does not easily retract.

1:47 Irrigation. Once all springs are removed, the subgaleal space is irrigated and hemostasis assured.

1:55 Closure. Layered closure of galea with 3-0 Vicryl and skin with 4-0 plain gut is performed. The spring removal procedure can be performed efficiently in approximately 15 minutes.

2:06 Dressing. Bacitracin is applied and a head wrap is optional.

\section{References}

1. Arko L IV, Swanson JW, Fierst TM, et al. Spring-mediated sagittal craniosynostosis treatment at the Children's Hospital of Philadelphia: technical notes and literature review. Neurosurg Focus. 2015;38(5):E7.

2. Lauritzen C, Sugawara Y, Kocabalkan O, Olsson R. Spring mediated dynamic craniofacial reshaping. Case report. Scand J Plast Reconstr Surg Hand Surg. 1998;32(3):331-338.

3. Shakir S, Humphries LS, Kalmar CL, et al. Hope springs 
eternal: insights into the durability of springs to provide long-term correction of the scaphocephalic head shape. $J$ Craniofac Surg. 2020;31(7):2079-2083.

4. David LR, Plikaitis CM, Couture D, et al. Outcome analysis of our first 75 spring-assisted surgeries for scaphocephaly. $J$ Craniofac Surg. 2010;21(1):3-9.

5. David LR, Proffer P, Hurst WJ, et al. Spring-mediated cranial reshaping for craniosynostosis. J Craniofac Surg. 2004;15(5): $810-818$

6. Lauritzen CGK, Davis C, Ivarsson A, et al. The evolving role of springs in craniofacial surgery: the first 100 clinical cases. Plast Reconstr Surg. 2008;121(2):545-554.

7. Rodgers W, Glass GE, Schievano S, et al. Spring-assisted cranioplasty for the correction of nonsyndromic scaphocephaly: a quantitative analysis of 100 consecutive cases. Plast Reconstr Surg. 2017;140(1):125-134.

8. van Veelen ML, Mathijssen IM. Spring-assisted correction of sagittal suture synostosis. Childs Nerv Syst. 2012;28(9): $1347-1351$.

\section{Disclosures}

The authors report no conflict of interest concerning the materials or methods used in this study or the findings specified in this publication.

\section{Author Contributions}

Primary surgeon: Lang, Swanson, Storm, Taylor. Assistant surgeon: Lang. Editing and drafting the video and abstract: Lang, Kalmar, Swanson, Shakir, Storm, Heuer. Critically revising the work: all authors. Reviewed submitted version of the work: Lang, Kalmar, Shakir, Kennedy, Heuer, Bartlett, Approved the final version of the work on behalf of all authors: Lang. Supervision: Lang, Bartlett. Filming of video: Kalmar.

\section{Correspondence}

Shih-Shan Lang: Children's Hospital of Philadelphia, PA. chens4@email.chop.edu. 